\title{
Do social ao ambiental: \\ a mobilização pela responsabilidade social empresarial no Brasil e na Argentina em perspectiva histórica comparada
}

\author{
Luciana de Oliveira ${ }^{*}$
}

\begin{abstract}
Resumo
Neste artigo, pretende-se compreender porque o empresariado assumiu a divulgação de discursos e práticas de Responsabilidade Social Empresarial (RSE) no Brasil, ao passo que foi a sociedade civil organizada que o fez na Argentina. Desse modo, além do esforço comparativo - sempre útil para apontar semelhanças e diferenças, criar escalas e sugerir generalidades compreende-se que há uma lacuna na abordagem do tema que precisa ser suprimida: a construção de um marco histórico sobre a ação empresarial em relação à questão social. Como corolário, pretende-se entender o quadro contextual que reveste de sentidos a expressão RSE em cada realidade nacional analisada, bem como apontar a passagem da relevância da questão social à relevância da questão ambiental, levando em consideração o fato de que mesmo sendo uma temática global ela não é homogênea.
\end{abstract}

Palavras-Chave: Responsabilidade Social Empresarial; Questão social; Sustentabilidade; História comparada; Brasil; Argentina.

Responsabilidade Social Empresarial - RSE - é, atualmente, uma noção de uso corrente em todo o mundo. Empresas dos mais diversos segmentos da economia a utilizam como forma de divulgar sua "boa" conduta e expressar uma imagem associada à preocupação com as coisas públicas, não apenas com o lucro privado. Além disso, o tema tem sido amplamente debatido nas esferas estatal, privada e da sociedade civil organizada, bem como no âmbito das agências internacionais, sem falar na comunidade acadêmica. De maneira geral, o movimento em torno da Responsabilidade Social Empresarial traduz certa mobilização, apoiada por entidades, sindicatos e associações (empresariais ou não), a respeito da necessidade de atuação das empresas no âmbito de investimentos tipicamente estatais ou de interesse público - como educação, saúde,

*Doutora em Ciências Sociais pela Universidade Federal de Minas Gerais (UFMG). Professora adjunta do Departamento de Comunicação Social da Universidade Federal de Minas Gerais (UFMG). Pesquisadora associada do Grupo de Pesquisa em Imagem e Sociabilidade (GRIS) da UFMG. E-mail: lucianaoliveira@ufmg.br. 
alimentação, cultura, meio ambiente. Essa mobilização se fundamenta na visão de que gerar lucro não é o objetivo único das empresas: elas devem ser também capazes de gerar valor social e ambiental. Nisso consiste sua responsabilidade social.

Para compreender a constituição de um campo de discursos e ações empresariais relativos à Responsabilidade Social, vale assinalar alguns dos principais marcos recentes como a criação, em 1990, da International Business Leaders Forum na GrãBretanha, e da associação empresarial Business for Social Responsibility nos Estados Unidos, no ano de 1992. Há ainda a criação do World Business Council for SustainableDevelopment, no ano de 1995 e, posteriormente, em 1997, a criação do grupo de trabalho denominado Corporate Social Responsability Europe. Esses são alguns exemplos da crescente atenção que o mundo empresarial tem dado ao tema da responsabilidade social e à sua institucionalização. O desenvolvimento de normas de certificação é também ilustrativo dos esforços por aplicar padrões e indicadores como estratégias para orientar o comportamento empresarial. Entre as mais importantes, destacamos a série 14000, da International Organization for Standardization - ISO, que trata da qualidade dos processos da empresa em relação à gestão ambiental; a Social Accountability, SA 8000, centrada nas condições de trabalho, criada pelo Órgão de Credenciamento do Conselho de Prioridades Econômicas - CEPAA, ligado à ONU; e a norma Accountability 1000, AA1000, criada pelo Institute of Social and Ethical Account Ability - ISEA, de Londres, que é uma ferramenta de gestão que engloba o processo de levantamento de informações, a auditoria e o relato social e ético, com enfoque no diálogo com as partes interessadas - stakeholders internos e externos. Na mesma linha, o lançamento do Global Reporting Initiative - GRI, em 1997 e, no ano de 2000, a publicação da primeira guia de GRI é também um bom exemplo de esforço orientado para a promoção de relatórios comparáveis em escala internacional do comportamento e do desempenho das empresas nos seus aspectos econômicos, ambientais e sociais. Sob iniciativa da ONU, temos o lançamento, em 1999, do Pacto Global, um programa que apela em particular ao setor empresarial por sua adesão a valores e princípios em matéria de direitos humanos, de normas laborais, de meio ambiente e de luta contra a corrupção e as Metas do Milênio de 2000 (compostas por oito macro objetivos voltados à erradicação da pobreza, diminuição das desigualdades e compromisso com a sustentabilidade do planeta, a serem atingidos até 2015). O Brasil tem duas contribuições importantes, reconhecidas internacionalmente, em termos de institucionalização e normatização do comportamento socialmente responsável: o 
modelo de balanço social desenvolvido pelo Instituto Brasileiro de Análises Sociais IBASE (1997) - e os indicadores de responsabilidade social desenvolvidos pelo Instituto Ethos (2000). No campo das métricas de RSE, a mais recente norma internacional é a ISO 26.000, lançada em 2010, cuja elaboração envolveu os esforços de aproximadamente 450 especialistas de 99 países em um trabalho de construção coletiva com forte protagonismo brasileiro. Esses são alguns exemplos da importância crescente do tema da responsabilidade social bem como da atenção a ele dada por algumas organizações nacionais e supranacionais.

Como pano de fundo do debate sobre razões e fundamentos da RSE, existe toda uma discussão sobre as transformações socioeconômicas e culturais recentes agrupadas sob controversos conceitos como os de globalização, sociedade pós-industrial, sociedade em rede, modernidade tardia, modernidade líquida, pós-modernidade, era da informação. Tais transformações estão moldando novos cenários e tendências e, como não poderia deixar de ser, têm transformado as formas de atuação das empresas nas sociedades contemporâneas, assim como têm remodelado seus interesses e suas formas de organização e luta política por reafirmá-los.

Os anos 1980 fizeram a passagem para um novo cenário empresarial, sobretudo a partir da chamada revolução da informação, que envolve não somente o incremento de novas tecnologias na produção de bens e serviços, mas, também, uma maior agilidade e flexibilidade nos processos organizacionais. Estabeleceu-se um ambiente de competição acirrada que promoveu, entre outras coisas, esforços permanentes em direção à chamada satisfação de clientes e consumidores que, por sua vez, vêm se tornando cada vez mais ciosos e exigentes de seus direitos. Estruturalmente, porém, tais mudanças podem ser associadas a um novo padrão de acumulação do capital, em função da crise do modelo fordista, abalado interna e externamente (HARVEY, 2001). Harvey denomina essa readequação do capitalismo global de "acumulação flexível”, em que a produção em larga escala, altamente padronizada e a ser consumida em massa, é paulatinamente substituída pela produção menor e mais ágil, que visa atender demandas especializadas. Essa nova forma de regulação do capital admite ou necessita de formas de trabalho igualmente flexíveis, como as contratações temporárias e a terceirização de certas etapas da produção. Porém, o Estado "encolheu” no que se refere à intervenção na economia, passando a atuar e arbitrar cada vez menos sobre o funcionamento do mercado, de acordo com os cânones ditados pelo chamado Consenso de Washington. A sociedade civil, em contraponto, se (re)organizou com a multiplicação das organizações não- 
governamentais e, mais amplamente, do chamado Terceiro Setor, em torno de alternativas para os graves problemas sociais dos nossos dias, cuja influência é, em muitos casos, global.

É nesse novo cenário que as empresas têm buscado afirmar outro modo de atuação. Como resposta aos desafios de competitividade e produtividade, surge um forte discurso da qualidade de produtos e serviços que se volta tanto para os processos de produção (distribuição, comercialização, logística etc.) quanto para a necessidade de um tratamento acurado dos relacionamentos compreendidos na atividade empresarial (empregados, fornecedores, clientes, comunidade, investidores e acionistas, poderes públicos, meios de comunicação, entre outros). Entre as ações empresariais voltadas para a comunidade, se enquadram aquelas de caráter social e/ou cultural, sob a forma de financiamentos, apoio profissional ou atuação direta em projetos sociais e culturais, em áreas cuja responsabilidade antes era considerada exclusiva do Estado. Por tudo isso, o movimento pela adoção de práticas de RSE representa um caso exemplar das redefinições de fronteira entre público e privado na contemporaneidade, bem como de novas configurações e modalidades de relação entre atores estatais, empresariais e da sociedade civil. É nesse sentido que retomaremos a caracterização do movimento pela RSE, não buscando sua origem em termos cronológicos, mas, sim, analisando os pontos que o fundamentam.

A ideia de que as empresas, só recentemente, têm assumido responsabilidades fora de sua esfera tradicional de atuação, ou seja, a esfera econômica, passando a atuar na esfera social e na geração de valor ambiental, é, no mínimo, apressada. Para não dizer equivocada. Se considerarmos, por exemplo, práticas como as de caridade, filantropia, trabalho voluntário e educação para o trabalho, vemos claramente que são práticas que sempre existiram, perpassando a relação entre Estado, Sociedade Civil e Empresas, bem como constituindo o que chamamos de espaço público. Por outro lado, vale dizer que existiram, na maioria dos casos, sem os massivos investimentos e esforços tanto de auto reconhecimento quanto de publicização junto à sociedade em geral com que ocorrem atualmente. Para além de serem mais comunicados ou visíveis, os investimentos da iniciativa privada bem como a maior organização da sociedade civil em relação às questões sociais e ambientais parecem de fato ter ganhado uma proporção inédita. $\mathrm{O}$ incremento em quantidade, a substantiva diversificação desses investimentos, sua apresentação como traço constitutivo da imagem de uma empresa de sucesso e, 
acima de tudo, o seu delineamento como uma espécie de "movimento" chamam especial atenção.

Trata-se de um movimento que vem se constituindo como um campo de discursos variados, mas em cruzamento, por onde passam as correntes reformadoras do movimento empresarial dos anos 1990; os herdeiros das tradições liberais e sua defesa das diversas formas de associativismo; os grupos ligados a qualquer forma institucionalizada de religião, bem como líderes praticantes de uma espiritualidade não institucionalizada e/ou "filosófica"; o discurso ecológico e seus diversos representantes, entre outros. Assim, o movimento da chamada RSE se realiza como parte de um processo mundial que envolve um conjunto de práticas institucionalizadas, valorizadas de modo explícito como imprescindíveis para a construção de uma imagem de sucesso das empresas, e de modo implícito, como forma de atuação política e social.

Com efeito, a rápida massificação do uso da expressão "responsabilidade social" associada as ações empresariais tem mais obscurecido do que esclarecido a sua leitura como fenômeno social. Incrustado na fronteira entre público e privado, talvez mesmo como importante contributo ao seu delineamento nos últimos vinte anos, muito se fala da RSE como fenômeno gerencial. Sua compreensão, ainda restrita aos estudos de caso e, muitas vezes, presa à descrição e à fala dos próprios atores envolvidos, necessita, em nossa avaliação, tanto de maior vigor teórico quanto de perspectiva histórica para aprofundar certas análises em circulação. Em relação aos casos nacionais investigados em nossa pesquisa, defende-se, de acordo com a análise de Agüero (2002), que o movimento de difusão do tema na Argentina representa um modelo citzen driven, já que sua liderança está na sociedade civil organizada em contraponto ao caso do Brasil, que é do tipo business driven, liderado pelos próprios empresários. Por que isso ocorre? Esse ponto é de fundamental importância, pois oportuniza verificar como os sentidos dos termos da agenda de negócios global se ressignificam nos contextos nacionais brasileiro e argentino de acordo com certa tradição histórica que ordena as relações entre Estado, mercado e sociedade.

\section{Breve retrato do campo da RSE no Brasil e na Argentina}

Entre as entidades observadas, o quadro 1, abaixo, identifica e sintetiza quais são as mais importantes "vozes" promotoras do tema da RSE no Brasil e na Argentina, elaborado com base em pesquisa de campo realizada nas duas realidades nacionais 
escolhidas para a comparação ${ }^{1}$. O quadro busca apresentar as instituições já alinhadas segundo um critério de correspondência, o que não significa que as instituições tenham o mesmo grau de relevância relativo em cada realidade nacional.

Quadro 1 - Entidades Promotoras da RSE no Brasil e na Argentina

\begin{tabular}{|c|c|c|}
\hline Brasil & Argentina & Critério(s) de correspondência \\
\hline Ethos & $\begin{array}{l}\text { Valos/Fundación } \\
\text { Tucumán }\end{array}$ & $\begin{array}{l}\text { São entidades organizadas por empresários e } \\
\text { compostas por empresas associadas que estabelecem } \\
\text { a relação entre os desafios da empresa e os problemas } \\
\text { da nação (embora a Valos e a Fundación Tucumán } \\
\text { tenham abrangência regional - respectivamente } \\
\text { províncias de Mendoza e de Tucumán). }\end{array}$ \\
\hline Cebds & Ceads & $\begin{array}{l}\text { São escritórios regionais do World Business Council } \\
\text { for Sustainable Development - WBCSD que } \\
\text { trabalham fundamentalmente com o tema do } \\
\text { desenvolvimento sustentável mas também difundem } \\
\text { uma cultura de negócios baseada na Responsabilidade } \\
\text { Corporativa. }\end{array}$ \\
\hline Amcham-SP & Amcham Argentina & $\begin{array}{l}\text { São entidades precursoras da divulgação do tema e } \\
\text { sua principal contribuição é a realização de uma } \\
\text { premiação a empresas e empresários que tiveram } \\
\text { projetos destacados no campo da RSE. Trabalham } \\
\text { com o conceito de Cidadania Empresarial. }\end{array}$ \\
\hline Gife & GDFE & $\begin{array}{l}\text { São entidades que reúnem fundações de empresas e } \\
\text { trabalham com o conceito de Investimento Social } \\
\text { Privado com o objetivo de profissionalizar as ações } \\
\text { filantrópicas por elas realizadas. }\end{array}$ \\
\hline ADCE & $\mathrm{ACDE}$ & $\begin{array}{l}\text { São entidades que reúnem empresários cristãos } \\
\text { (católicos) e que trabalham o conceito de RSE como } \\
\text { relacionamento de valor com as partes interessadas. } \\
\text { Valor no sentido moral cristão inspirado na Doutrina } \\
\text { Social da Igreja. }\end{array}$ \\
\hline Fiesp & Cac & $\begin{array}{llrr}\text { São entidades } & \text { de representação } & \text { de } & \text { interesses } \\
\text { empresariais } & \text { (industriais } & \text { e } & \text { comerciais } \\
\text { respectivamente) } & \text { que vêm } & \text { se } & \text { dedicando } \\
\text { paralelamente à divulgação da } & \text { RSE } & \text { (embora em } \\
\text { proporções bastante diferentes). }\end{array}$ \\
\hline- & Aacrea & $\begin{array}{l}\text { É uma entidade de representação dos interesses } \\
\text { empresariais rurais que tem buscado discutir a } \\
\text { questão da RSE, sobretudo em relação à questão } \\
\text { ambiental, nos seus congressos anuais. }\end{array}$ \\
\hline \multicolumn{3}{|c|}{ ENTIDADES DA SOCIEDADE CIVIL ORGANIZADA } \\
\hline Brasil & Argentina & Critério(s) de correspondência \\
\hline Ibase & El Otro & $\begin{array}{l}\text { Entidades da sociedade civil que têm, dentro de um } \\
\text { espectro mais amplo de atividades, um grupo de } \\
\text { trabalho em RSE, ambas são afiliadas da Red }\end{array}$ \\
\hline
\end{tabular}

\footnotetext{
${ }^{1}$ A pesquisa incluiu a formação de um banco de dados com matérias e artigos assinados, coletados em jornais (Folha de S. Paulo, 1994-2008, e O Globo, 2003-2008, no Brasil; La Nación, 1998-2008, e Clarín, 1995-2008, na Argentina); participação em eventos das entidades promotoras da RSE no Brasil e na Argentina e entrevistas em profundidade com informantes privilegiados. No caso argentino, levou-se ainda em consideração para a elaboração do quadro o Mapeo de Promotores de Responsabilidad Empresaria en Argentina. Ver: www.mapeo-rse.info.
} 


\begin{tabular}{|c|c|c|}
\hline & & $\begin{array}{l}\text { Puentes. El Otro tem certa afinidade com o GAO - } \\
\text { Grupo de Articulação das ONGs Brasileiras na ISO } \\
26000 \text { já que é a representante da sociedade civil no } \\
\text { Comité Espejo Argentino. }\end{array}$ \\
\hline Transparência Brasil & Poder Ciudadano & $\begin{array}{l}\text { Entidades da sociedade civil (no caso da primeira } \\
\text { com forte presença e liderança empresarial) que } \\
\text { trabalham no sentido de promover o controle externo } \\
\text { das contas públicas e o combate à corrupção. }\end{array}$ \\
\hline- & Foro Del Sector Social & $\begin{array}{l}\text { Não tem correspondente direto no Brasil pois é uma } \\
\text { entidade que aglutina um conjunto de organizações } \\
\text { do terceiro setor em prol da promoção do conceito de } \\
\text { RSE. Tem algumas afinidades com o GAO que } \\
\text { também propõe esse tipo de ação, mas com foco na } \\
\text { norma ISO } 26000 \text { e com algumas ações pontuais da } \\
\text { ABONG. }\end{array}$ \\
\hline- & Iarse & $\begin{array}{l}\text { Não tem correspondente direto no Brasil pois é uma } \\
\text { entidade organizada por não-empresários (ex-gerentes } \\
\text { de fundações de empresas com formação em Serviço } \\
\text { Social) mas que produz material similar ao do Ethos, } \\
\text { guardando com ele correspondência indireta } \\
\text { (afinidade de pensamento) e direta (LuisUlla, diretor } \\
\text { executivo da entidade, é membro do Conselho } \\
\text { Internacional do Ethos e o Iarse traduziu vários } \\
\text { materiais do Ethos para o espanhol e trabalha na } \\
\text { divulgação dos mesmos) }\end{array}$ \\
\hline- & Foro Ecumenico & $\begin{array}{l}\text { Não tem correspondente direto no Brasil, pois é uma } \\
\text { entidade organizada por um jornalista (promotor do } \\
\text { evento Desafio Empresario financiado pelo Banco } \\
\text { Francés) que congrega um conjunto de instituições } \\
\text { religiosas de distintas confissões já que as religiões } \\
\text { têm afinidades históricas com o trato da questão } \\
\text { social. Discute sobre RSE relacionando-a com o tema } \\
\text { da ética. }\end{array}$ \\
\hline- & Amia & $\begin{array}{l}\text { Não tem correspondente direto no Brasil pois é uma } \\
\text { associação judaica que recentemente lançou o } \\
\text { Programa Valor para incentivar medidas de RSE, } \\
\text { sobretudo em pequenas e médias empresas e cadeia } \\
\text { de valor das grandes empresas. }\end{array}$ \\
\hline
\end{tabular}

Fonte: OLIVEIRA, 2010.

Quais são as diferenças mais notáveis entre os casos a partir da observação do quadro 1? No caso da Argentina, há uma grande quantidade de organizações da sociedade civil que trabalham com a divulgação do tema e a sua força (presença no espaço público, capacidade de mobilização e liderança) é, olhando-se para o contexto interno, maior do que a das entidades de origem empresarial, e muito menor na comparação com o Brasil. Inicialmente, especialmente após a crise de 2001, quando o tema ganha de fato importância, a tônica dos discursos das ONGs era a do controle externo das empresas, algo que era formulado assim: as empresas estão muito poderosas no cenário da globalização, é preciso que a sociedade civil controle as empresas e direcione os investimentos sociais papel que foi amplamente enfatizado pelo Foro 
delSector Socia ${ }^{2}$. Os grupos organizados da sociedade civil reclamavam, com isso, o papel de protagonistas no campo da questão social justificado pelo know-how e conhecimentos de causa adquiridos com a experiência e também pela legitimidade, já que as organizações da sociedade civil têm alto grau de confiança, enquanto empresas/empresários, ao contrário, têm baixo grau de confiança na sociedade argentina. Atualmente, essa postura parece estar mudando pelo reconhecimento, ao menos normativo, sobre a necessidade de ações parceiras com as empresas frente à envergadura dos problemas sociais a serem enfrentados - a chamada nova pobreza argentina - embora as empresas sejam ainda vistas com muita desconfiança.

A coleta de dados realizada em dois jornais de cada país, também nos dá uma visão de como o tema da RSE vem sendo incorporado ao debate público de acordo com os quadros 2 e 3 .

\section{Quadro 2 - Total de Registros Recuperados sobre Entidades nos Jornais La Nación e Clarín (indicador de visibilidade midiática)}

\begin{tabular}{|l|c|c|}
\hline \multicolumn{1}{|c|}{ Entidade } & La Nación & Clarín \\
\hline Iarse & 39 & 3 \\
\hline GDFE & 2 & 0 \\
\hline Cac & 2 & 0 \\
\hline Ceads & 6 & 0 \\
\hline Aacrea & 34 & 14 \\
\hline ElOutro & 21 & 9 \\
\hline Foro Ecumênico & 26 & 16 \\
\hline Amia & 27 & 2 \\
\hline Foro Del Sector Social & 35 & 10 \\
\hline Poder Ciudadano & 16 & 3 \\
\hline Idea & 9 & 2 \\
\hline ACDE & 17 & 7 \\
\hline Valos & 9 & 0 \\
\hline
\end{tabular}

Fonte: OLIVEIRA, 2010.

O breve retrato do debate público da RSE nos meios impressos de comunicação na Argentina, complementado pelos demais dados coletados na pesquisa, nos mostra os seguintes aspectos. Há uma grande fragmentação e nenhuma liderança. Os empresários locais e os líderes empresariais que atuam nas grandes empresas têm uma preocupação que se volta para dentro do próprio negócio, mas não assumem, ou sequer cogitam, tomar liderança de um movimento mais amplo de aproximação entre Estado e

\footnotetext{
${ }^{2}$ O Foro del Sector Social (ver http://www.forodelsectorsocial.org.ar) é uma federação de associações civis e fundações que atuam em todo o território nacional argentino. Teve forte protagonismo na introdução do debate da RSE na Argentina em 2001, passou por um período de reestruturação e atualmente agrupa 230 organizações, sendo que algumas destas são confederações ou redes.
} 
sociedade. A grande quantidade de entidades que atuam é inversamente proporcional à força que o tema adquire como movimento, ou seja, muito pequena.

No caso do Brasil, observa-se de acordo com o quadro 3 abaixo, uma maior presença do tema no debate público como também uma maior concentração em entidades empresariais (exceção é o Ibase), além de uma liderança do Instituto Ethos e a marcante presença de entidades empresariais tradicionais como a Fiesp.

\section{Quadro 3 - Total de Registros Recuperados das Entidades nos Jornais - Brasil (indicador de visibilidade midiática)}

\begin{tabular}{|l|c|c|}
\hline \multicolumn{1}{|c|}{ Entidade } & Folha de São Paulo & O Globo \\
\hline Instituto Ethos & 193 & 51 \\
\hline Fiesp & 68 & 6 \\
\hline Gife & 25 & 7 \\
\hline Ibase & 14 & 16 \\
\hline Cebds & 4 & 1 \\
\hline ADCE & 0 & 0 \\
\hline Amcham-SP & 2 & 1 \\
\hline Transparência Brasil & 8 & 3 \\
\hline
\end{tabular}

Fonte: OLIVEIRA, 2010.

Observando os quadros acima, nossa hipótese é a de que a dimensão política - a transformação do tema numa questão pública de relevância -, constitutiva da mobilização em torno da RSE no Brasil, está ausente no caso argentino, nem há uma liderança assumida por nenhum dos atores que jogam no campo. Afora essa dimensão, todas as demais - práticas gerenciais de RSE com diferentes finalidades e encaradas com distintos graus de profundidade, métricas, prêmios circulam pelo campo, embora com uma diferença de grau em relação ao caso do Brasil.

\section{A RSE e seus antecedentes no Brasil e na Argentina: a perspectiva histórica}

De acordo com pesquisas realizadas no contexto latino-americano (RED PUENTES, 2004; RED INTERAMERICANA DE RSE, 2005; FORUM EMPRESA, 2009), o Brasil e o México são os países onde o tema da RSE encontra maior enraizamento nas culturas organizacionais das empresas, além de maior visibilidade pública. A Argentina, por seu turno, encontra-se, digamos, numa fase intermediária: o tema é objeto de discussão e de inúmeras práticas nas empresas, embora tenha ainda pouca capilaridade como objeto de debate público. Aqui, se apresentam os resultados de uma análise histórica comparativa que pretende ajudar a preencher uma lacuna na 
literatura. Quase não existem estudos comparativos na América Latina sobre o tema da RSE. Como anotou Oliveira (2006), existe uma vasta produção acadêmica sobre a chamada cidadania corporativa, porém essa produção está voltada para uma discussão da dinâmica interna de cada um dos países latino-americanos e não para uma comparação entre eles.

O ponto que buscamos elucidar é por que o movimento da RSE é empresarial no Brasil, enquanto na Argentina está ligado à sociedade civil organizada e, para tanto, nos debruçaremos sobre a história desses países, sobretudo, no que diz respeito às relações entre empresariado e a questão social no quadro mais amplo das relações Estado, mercado e sociedade. A questão social, entendida como uma contradição em torno da qual "uma sociedade experimenta o enigma de sua coesão e tenta afastar o risco de sua fratura" (CASTEL apud CARDOSO JR.; JACCOUD, 2005, p. 184), varia historicamente, por isso a longa duração é de extrema importância para o seu entendimento.

Um estudo dessa natureza deve levar em conta a diferença entre culturas empresariais, a qual se relaciona às distintas trajetórias econômicas, sociais e políticas do Brasil e da Argentina. É evidente que, ao lado das diferenças, há semelhanças, que, em se tratando da dimensão cultural, têm a ver com a origem ibérica dos nossos costumes e instituições. A presença dominante da Igreja Católica ao longo de vários séculos constitui, talvez, a expressão principal dessa origem ibérica, ao menos no que se refere às concepções e modalidades de ação social de cunho filantrópico. Durante a época colonial, por exemplo, iniciativas de assistência social emanaram, em ambos os países, quase exclusivamente do campo religioso. Na Argentina, enquanto o Estado colonial cuidava das questões sanitárias, a Igreja Católica, especialmente através do clero regular, realizava a chamada assistência social caritativa. Mas, além deste trabalho, existiam instituições que, embora sob a sombra da Igreja, tinham aspectos mais independentes e incluíam a participação de leigos. Tais instituições mantinham hospitais, casas para órfãos e mulheres carentes. Além da assistência social, cuidava-se também da educação (PASANANTE, 1987; THOMPSON, 1995; CAMPETELLA; BOMBAL, 2000a e 2000b). Algo semelhante ocorreu no Brasil, onde as Santas Casas começaram a atuar muito cedo, representando uma antiga modalidade de assistência originária de Portugal. Surgiram também irmandades, confrarias de leigos que cumpriam papéis, ao mesmo tempo, rituais e assistenciais (QUIROGA, 2005). 
A partir da independência (no início do século XIX), houve na Argentina uma transferência progressiva e cheia de altos e baixos das obras de caridade em poder de religiosos à responsabilidade de organizações laicas e com um maior controle do Estado. Daí, até o início do século XX, foi um período de grande prosperidade no que se refere à constituição de entidades privadas de assistência. Nesse sentido, o exemplo mais notável é o da Sociedade de Beneficência - SB, fundada em 1823, responsável pelas principais tarefas de filantropia e assistência social no país, até meados do século $\mathrm{XX}$, de forma privada, porém, em grande parte, com fundos públicos. Era uma entidade que reunia a elite econômica da agroexportação e as grandes famílias da política e da alta administração. Na prática, entretanto, essa passagem significou mais uma troca de administração, mantendo-se em essência os mesmos valores e instrumentos de solidariedade social. Paralelamente, uma ampla rede de solidariedade social no âmbito da sociedade civil se formou com as sociedades de socorros mútuos, as cooperativas, as associações de bairro, as bibliotecas e clubes privados e as associações de imigrantes. Os confrontos entre capital e trabalho, face mais visível da questão social nas sociedades modernas, foram bastante fortes na Argentina, especialmente no início do século e na década de 1910. Mas foram contornados do ponto de vista político com o sufrágio universal da Lei Saenz-Peña, de 1912, e algumas garantias trabalhistas como as primeiras caixas de aposentadoria (ROMERO, 2001; ROMERO, 2004).

No período agroexportador (1880-1930), permaneceu na Argentina um projeto de nação fundado na dicotomia civilização/barbárie, do qual a expressão maior é o pensamento da geração de 1880 (FAUSTO; DEVOTO, 2004). Cardoso (1971) enxerga, nesse período, a capacidade da elite proprietária de estabelecer um domínio solidamente baseado numa economia exportadora em expansão, como também em um projeto de desenvolvimento racionalizado pela ideologia liberal, calcado no livre jogo do mercado e justificado por representar os interesses de uma maioria de consumidores e não de uma minoria de produtores. As contestações, advindas da pressão popular, dirigiam-se à abertura do sistema político e da melhor distribuição da renda e foram, ao menos, parcialmente atendidas. $\mathrm{Na}$ Argentina, a participação popular tem um caráter simbólico de peso expressivo. De acordo com Glik (s/d, p. 10) "nos livros didáticos, a figura do Cabildo Abierto e a frase 'O povo quer saber de que se trata' transferem a imagem de uma primeira participação popular nos assuntos de governo”. A participação popular sob convocatória das elites, por exemplo, nas passeatas e nos protestos de rua revela, 
por um lado, um viés da dominação, mas por outro a importância simbólica dos trabalhadores como partícipes das reivindicações.

No Brasil, a evolução foi diferente. Não surgiu nenhum órgão tão poderoso e abrangente. $\mathrm{O}$ engajamento de elites econômicas e de empresas em ações sociais nãolucrativas sempre acompanhou a trajetória do capitalismo brasileiro, mas como um fenômeno secundário marcado pelas motivações de caráter pessoal (consciência religiosa e/ou filosófica) quase insignificantes frente aos fortes níveis de desigualdade social. As ações não-econômicas desses agentes econômicos, historicamente, sempre foram importantes para demarcar suas fronteiras de classe, tanto no sentido do autoreconhecimento quanto na delimitação de fronteiras em relação a outras classes sociais. Isso é um ponto comum com a Argentina. Contudo, uma diferenciação que se coloca importante para o nosso ponto é a visão das elites sobre os grupos organizados da sociedade civil e sobre a população de um modo geral. No Brasil, as elites políticas e empresariais, tenderam historicamente a conceber a sociedade civil como frágil (o pobre é despreparado para a participação) e os movimentos de protesto ou de insatisfação social para com os dirigentes - quando visíveis no espaço público - tratados como "bagunça", desordem (CARVALHO, 1996; VALADARES, 1991), inclusive nos conflitos entre capital e trabalho que foram fortemente reprimidos pelo Estado. Os movimentos associativos - sociedades de socorros mútuos, cooperativas e outros - que poderiam representar uma rede de solidariedade social paralela ao Estado, sempre foram vistos com desconfiança e controlados pela via legal, quando não diretamente combatidos (VISCARDI; JESUS, 2007).

De modo sintético, observa-se, no período agroexportador brasileiro, a presença de uma questão social grave (que incluía a negligência em relação aos negros após a abolição e a falta de regulamentação do mercado de trabalho), movimentos populares fracos, ou melhor dizendo, enfraquecidos pela força repressora do poder estatal oligárquico, pela força política das elites (expressa, por exemplo, por meio de menosprezo na imprensa), bem como de uma ação social impositiva na dimensão estatal, liberal, empresarial (a pobreza é problema do pobre), bem como esparsa e fragmentada na dimensão associativa. Nesse período, emerge um projeto de nação fundado na autonomia frente à tutela colonial, não de um povo, mas de uma pequena parte dele e sustentado simbolicamente na hibridização cultural. "Conciliação" e "cordialidade" tanto na política partidária como na racial (da qual é expressão o branqueamento como ideologia racial na primeira República), ao invés das convulsões 
militares e civis, das rupturas e refundações, da universalização da educação e dos direitos civis presentes na Argentina, se tornaram os elementos fundantes da Nação, ou melhor dizendo, dos dois brasis, conforme a formulação de Florestan Fernandes (1975).

O Brasil é uma nação (ou melhor, duas nações) constituída por um Estado forte e uma sociedade civil fraca. Na Argentina, ao contrário, "o caráter tardio da formação do Estado permaneceu solidário de uma grande vitalidade associativa e de uma estruturação particularmente robusta dos grupos dirigentes" (ROUQUIÉ, 1985, p. 14). Assim,

[...] de um lado, o padrão argentino se configura por um processo tardio de formação do Estado nacional, enquanto que, no caso brasileiro, o Estado se constitui precocemente. De outro lado, no plano da dinâmica liberal, o padrão é praticamente inverso: enquanto na Argentina o ritmo de expansão da arena política é mais forte e amplo, no Brasil, ele se desenvolve de forma mais lenta e restrita. (TRINDADE, 1985, p. 51).

Enquanto na Argentina os setores mais numerosos da nação se transformaram com os avanços da economia agroexportadora, no Brasil eram setores mais limitados os que se transformavam.

No que tange à disputa por hegemonia entre o setor privado e o Estado em relação à questão social, uma fase de especial interesse foi a de meados do século XX. $\mathrm{Na}$ Argentina, passado o longo momento de retrocesso conservador conhecido como Década Infame, a ascensão de Perón resultou na incorporação, pelo Estado, da política social, sendo delegada aos sindicatos, a sua execução. Como expressão da nova correlação entre o Estado e o setor empresarial, a Sociedad de Beneficencia foi substituída pela Fundação Eva Perón. A rede de solidariedade social representadas pelas sociedades de socorros mútuos foi incorporada às ações estatais em paralelo ao redesenho dos sindicatos por categoria de trabalhadores e com abrangência nacional. Assim, o peronismo desenvolveu um sistema nacional de segurança social massivo que cobriu a praticamente todos os trabalhadores, além de tê-la assumido como um mecanismo de redistribuição econômica que o Estado tem tanto a necessidade quanto a obrigação de proporcionar. Vale dizer que até a emergência de Perón e do nacional-populismo na Argentina, os interesses da oligarquia rural prevaleciam sobre os interesses industriais. Mas se os últimos passam a valer, não foi por pressão política dos empresários industriais, mas sim como um projeto de Estado. Os industriais, por sua vez, não desafiaram inicialmente a Perón, mas em pouco tempo a força política dele os coloca sem reconhecimento como interlocutores do Estado (a Unión Industrial 
Argentina - UIA - sofre intervenção estatal, a Confederación Argentina del Comercio, la Industria y la Producción - CACIP - desaparece, enquanto a Sociedad Rural Argentina - SRA - e a Bolsa de Comércio se colocam numa posição resignada).

No Brasil, a Revolução de 1930 abriu uma fase de estatização da questão social, que se prolongou com a ditadura varguista do Estado Novo. Com o prenúncio da liberalização política, houve forte mobilização do empresariado no sentido de assumir papel estratégico, substituindo o Estado na arena social. A criação do Sistema S, destinado à educação para o trabalho e aos serviços sociais de atendimento aos trabalhadores e suas famílias, era expressão desse esforço. Tal projeto, é claro, correspondia ao desenho corporativo de organização das classes que vigorava no Brasil (como também na Argentina peronista).Aqui não alcançava a grande maioria da população, atendo-se apenas aos trabalhadores urbanos do mercado formal. Essa teria sido uma das razões pelas quais não logrou êxito o investimento que a elite empresarial fez para assumir maior protagonismo no regime democrático instituído em 1946. Uma hegemonia burguesa só se tornaria viável com a queda do regime populista, em 1964, mas então o empresariado se tornou parceiro dos militares em um regime ditatorial. $\mathrm{O}$ que se nota nesse período é que as elites empresariais brasileiras tiveram maior poder de penetração no aparato estatal que as elites empresariais argentinas, sempre mais afastadas dos assuntos públicos, especialmente daqueles que não estivessem relacionados à política econômica (JAUREGUI, 2002).

Assim, Brasil e Argentina, em momentos diferentes, tiveram uma legislação trabalhista e um arranjo sindical para buscar lidar com as desigualdades advindas da industrialização. O Estado argentino disputou a hegemonia da questão social com a sociedade civil, enquanto no Brasil a disputa foi mais diretamente negociada com os empresários, inclusive fazendo-lhes algumas concessões em termos de política econômica para que pudessem acatar a legislação (GOMES, 1979).

$\mathrm{Na}$ Argentina, o populismo peronista durou até 1955 e deu lugar a fases ditatoriais entremeadas de tentativas malogradas de regimes democráticos. Entre esses, houve o período do desenvolvimentismo, que como ideário econômico propunha a proteção das indústrias nacionais da concorrência de produtos estrangeiros com base na parceria entre capital privado, capital estatal e capital estrangeiro, mas o empresariado argentino se colocou numa posição distante do Estado, ao contrário do que ocorreu no Brasil (SIKKINK,1993). No Brasil, ganha força nesse momento, entre vários setores das elites, a ideia de que a solução para os problemas sociais (especialmente os conflitos 
entre capital e trabalho) deviam vir do desenvolvimento econômico via a entrada do país numa era de capitalismo avançado e que, portanto, os interesses da indústria eram os interesses da nação.

Já as ditaduras adotaram, via de regra, políticas econômicas liberal-privatistas que enfraqueceram substancialmente a capacidade estatal de implementar políticas públicas no campo social. Isso, em tese, abria espaço para o empresariado assumir papel mais ativo. A ideologia da segurança nacional deu novos contornos à questão da nação imaginada, sobretudo em face das consequências dos dois populismos, em ambos os casos com importante participação do empresariado. Na Argentina, há um retrocesso conservador (mais abrupto e avassalador que o da Década Infame), calcado num projeto de nação fundado na oposição civilização $\mathrm{x}$ barbárie, só que essa última agora representada pelas classes populares organizadas insurgidas contra a ordem. No Brasil, o par, segurança e desenvolvimento, é a base da doutrina militar-empresarial que anima o regime ditatorial. Nela, o desenvolvimento é condição para a segurança pois país seguro é um país mais rico (não tinham ideia de ampliação da nação do ponto de vista da incorporação, o crescimento é um mecanismo natural de solução do problema social).

O rendimento médio dos brasileiros aumentou no período do "milagre" (19681973) e o crescimento do PIB foi de $8,4 \%$ ao ano, incluindo aumentos de salário em alguns setores, como gerentes e operários qualificados da área industrial. A pobreza foi reduzida, mas a desigualdade aumentou e as condições de vida nas grandes cidades pioraram com o inchaço das periferias, o que justificou a famosa frase de Médici: "a economia vai bem, mas o povo vai mal." (FAUSTO; DEVOTO, 2004, p. 422-423). Mas, por mais paradoxal que possa parecer, os militares não foram totalmente omissos em relação às políticas sociais. Deve-se lembrar ainda que foi em 1971 que o regime autoritário deu um passo importante para a universalização da proteção social com a instituição do FUNRURAL (lembrando que o Estatuto do Trabalhador Rural promulgado em 1963 já previa a implementação da previdência) que destinava uma pequena pensão aos trabalhadores rurais que estavam fora do sistema de contribuições previdenciárias (uma garantia de renda mínima no sentido atual do termo).

Numa análise mais geral das políticas sociais do período militar, Cardoso Jr e Jaccoud (2005) anotam que: 


\begin{abstract}
A retração econômica observada a partir da segunda metade dos anos 1970 ampliou, durante a década de 1980 , a percepção de que a expansão da proteção aos riscos sociais desenhada pela política previdenciária assentavase em um processo de expansão do assalariamento que já encontrava seus limites. A inclusão dos trabalhadores ligados ao setor informal da economia e daqueles vinculados à economia familiar urbana e rural permanecia como um desafio para uma política de proteção social ainda largamente fundamentada no princípio do seguro social e majoritariamente financiada por contribuições sociais. Para manter-se coerente com os princípios contributivos que a sustentavam, a Previdência Social oscilava entre a concessão de benefícios de valores extremamente baixos e a simples não-cobertura. Ao lado do reconhecimento dos limites da política previdenciária, consolidou-se ainda a interpretação de que tanto a regulação da pobreza pela filantropia, como sua superação via desenvolvimento econômico, eram insuficientes para responder a um fenômeno que passava a ser caracterizado no debate nacional como estrutural. Abria-se o terreno então para que a pobreza passasse a ser focalizada como tema próprio e prioritário da ação social do Estado. (CARDOSO JR; JACCOUD, 2005, p. 92).
\end{abstract}

A persistência de uma questão social grave, embora minimizada em alguns casos e controlada por ações estatais, deve-se principalmente à falta de mecanismos distributivos mais efetivos. Por um lado, se os problemas da pobreza foram combatidos com integração dos trabalhadores formais aos sistemas de proteção social e, por outro lado, se o custo de vida foi reduzido e o acesso aos bens de consumo foi ampliado com políticas econômicas favoráveis à indústria nacional, não se verificou um passo maior no sentido de romper com a grande fratura que reinstala a realidade dos "dois brasis".

Já na Argentina, o período militar de 1976-1983 representou o desmanche do modelo substitutivo e o aprofundamento, agora deliberado e planejado, de algumas decisões liberalizantes tomadas no golpe de 1966, principalmente no governo de Ongania (até 1970). No diagnóstico do então ministro da Economia, José Alfredo Martínez de Hoz, de acordo com Romero (2004), o forte peso do Estado na vida econômica - por sua capacidade de intervenção ou pelo controle das importantes empresas públicas - gerava em seu entorno uma luta permanente dos interesses corporativos - dos distintos grupos empresariais e do sindicalismo - que afetavam a eficiência da economia e a própria estabilidade social e política. Por isso, a presença do Estado devia ser reduzida e sua ação diretiva tinha que ser substituída pelo jogo de forças do mercado, capazes de disciplinar e fazer eficientes a distintos setores. Também deveria ser reduzida a indústria nacional, orientada ao mercado interno $\mathrm{e}$ tradicionalmente protegida pelo Estado e, junto com ela, os poderosos sindicatos industriais, que eram um dos principais fatores da agitação social. Um vasto plano de obras públicas haveria de compensar o desemprego generalizado até que a economia 
encontrasse suas formas naturais de produção e reprodução. De acordo com Romero (2001), nessa perspectiva:

[...] el Estado intervencionista y benefactor, tal como se había constituido desde 1930, era el gran responsable del desorden social; en cambio el mercado parecía el instrumento capaz de disciplinar por igual a todos los actores, premiando la eficiencia e impidiendo los malsanos comportamientos corporativos. (ROMERO, 2001, p. 212).

Com a retirada do Estado da economia, no setor financeiro houve uma entrada maciça de capital estrangeiro no país - no vulgo, plata dulce ou dinheiro fácil - e o mercado foi invadido por grande quantidade de produtos estrangeiros. Nesse cenário, muitas empresas quebraram, principalmente, as de porte pequeno e médio. Porém, lado, a atividade financeira especulativa e os contratos com o Estado fortaleceram a posição dos grandes grupos econômicos nacionais que operavam em diversas atividades e aproveitavam os recursos disponíveis para adquirir empresas e torná-las rentáveis.

Entretanto, todo o período foi marcado pelo enfrentamento sangrento entre o Estado ditador e grupos civis. No contexto de interrupção da ordem constitucional, a oposição política e resistência civil migraram para associações de vizinhos e para as "unidades básicas" remanescentes do peronismo. Paladino e Mohan (2002) discutem da seguinte forma a conformação da questão social nesse período:

\begin{abstract}
Durante la dictadura, los entes estatales de acción social y de prestación de servicios públicos habían sido seriamente deteriorados por las políticas económicas. El creciente déficit fiscal impedía que el gobierno democrático implementara modelos de desarrollo y política social, en especial para confrontar un problema que comenzaba a hacerse crónico: la exclusión social. La caótica retirada del Estado fue parcialmente remplazada por asociaciones civiles, que trataron de compensar la falta de servicios públicos básicos, tales como: desarrollo urbano, educación, seguridad, etc. Por lo tanto, antes de las privatizaciones de los noventa, ya había existido un retraimiento del Estado en ciertas áreas de influencia. (PALADINO; MOHAN, 2002, p. 30).
\end{abstract}

Mas só com a abertura política, na década de 1980, é que se abriria nova oportunidade para disputa por hegemonia em relação à questão social - a qual foi evidenciada no Brasil, sobretudo, na Constituinte de 1987-88. O foco na inclusão social, a adoção não tão radical dos preceitos neoliberais, e a universalização da proteção aos cidadãos consagrada no texto constitucional, de 1988, descortina um novo momento na história do país. É claro que isso não quer dizer que por aqui tenhamos resolvido toda a questão social, mas que alguns passos importantes na direção da seguridade social 
foram dados paripassu a uma rearticulação da sociedade civil e uma maior participação social na arena pública com maior pluralidade de visões - incluindo-se aí as visões empresariais.

Como não poderia deixar de ser, as transformações sociais e econômicas desse período tiveram desdobramentos específicos na Argentina. A implementação de políticas econômicas liberais possibilitou a entrada maciça de capital estrangeiro e a privatização de empresas e serviços públicos. Com o regime de economia aberta, assiste-se ao desmantelamento progressivo das políticas de proteção social na Argentina que adotou radicalmente o modelo do Estado Mínimo. Em contraponto, a sociedade civil, sempre muito ativa, seguiu fazendo seu trabalho com expressivo crescimento do chamado Terceiro Setor, mas agora ele é um conta-gotas no mar de uma questão social que só se aprofundou desde os governos militares e que foi especialmente marcada pelo modelo neoliberal dos dois governos de Menem e da forte crise econômica e política de 2001. O processo de privatizações permitiu o ingresso de novas empresas internacionais no país e, junto com elas, novas exigências em relação à Responsabilidade Social Empresarial, mas não por acaso quem assumiu a sua promoção na forma de um movimento foram as organizações da sociedade civil.

No Brasil, assistiu-se nesse período a um crescimento do interesse das empresas na realização de projetos de diferentes tipos e em diferentes áreas sociais e ao forte engajamento de empresários na sua promoção. Esse movimento foi impulsionado pela criação do Grupo de Institutos, Fundações e Empresas - GIFE -, em 1995, pelo prêmio ECO (Prêmio de Contribuição Empresarial à Comunidade) da Câmara Americana de Comércio de São Paulo, e, muito especialmente, pela criação do Instituto Ethos de Empresas e Responsabilidade Social em 1998. Os projetos e as práticas das empresas no campo social se diversificavam bastante, espalhando-se pelas diversas regiões do país. No início da década, o IPEA registrou esse processo de expansão em vários estudos empíricos (PELIANO, 2000, 2001a, 2001b, 2001c; IPEA, 2005; 2006).

No início do século XX, a Argentina possuía uma das economias mais dinâmicas do mundo, enquanto o Brasil vivia uma difícil transição da escravidão para o regime de trabalho livre. Cem anos depois, o Brasil se tornou uma economia industrializada e bem diversificada, ao passo que o país vizinho não logrou avançar de forma sustentável após o esgotamento do antigo sistema agro exportador que lhe proporcionara tanta riqueza no passado. As burguesias dos dois países refletem esses padrões contrastantes de desenvolvimento, o que se evidencia nos seus movimentos de 
divulgação de discursos e práticas de RSE. Com tais traços históricos, é possível responder ao ponto que incitou à presente a reflexão. A não mobilização do empresariado argentino em relação à liderança da promoção e das práticas de RSE parece ter a ver com uma tradição histórica de afastamento do jogo político, sobretudo nas matérias que ultrapassam o âmbito das decisões econômicas. Entretanto, o protagonismo da sociedade civil, no que se refere à questão social, empresta-lhe a legitimidade necessária para assumir tal liderança. No Brasil, a situação é inversa.

\section{Do Social ao ambiental}

Blumer (1971) argumenta que os problemas sociais não emergem de condições objetivas, ou seja, por suas condições prejudiciais ou malignas como queriam os funcionalistas. Eles dependem de um reconhecimento social como questões de relevância política, assim como é da definição coletiva do que é um problema social que emergem formas de vê-lo e de imaginar possíveis soluções. Mais uma vez o que assistimos na transição da mobilização em torno da RSE e sua passagem à defesa da sustentabilidade é muito diferente no Brasil e na Argentina. Não somente pela diferença temporal, mas também pelo enfoque e pela condução pública dada ao debate pelas suas lideranças.

No caso do Brasil, as primeiras movimentações para afirmar o debate sobre sustentabilidade, como pauta central das entidades por nós observadas, datam de $2006 \mathrm{e}$ 2007. Vale lembrar que, em 2006, é publicado o Relatório Stern ${ }^{3}$ e que, em 2007, ocorre a divulgação do quarto relatório do Painel Intergovernamental de Mudanças Climáticas - IPCC da ONU. Na Argentina, acompanhando a importância da temática ambiental no cenário internacional, houve também uma maior valorização da sustentabilidade. Notase, no caso argentino, que as entidades promotoras da RSE estão trabalhando numa fronteira conceitual híbrida entre RSE e Desenvolvimento Sustentável, mas não fizeram a opção estratégica pela promoção com maior ênfase do segundo como no caso do Brasil.

A sustentabilidade ambiental está na pauta das atividades das entidades da sociedade civil argentinas nas quais são abordados temas como consumo desenfreado

\footnotetext{
${ }^{3}$ O Relatório Stern, assim nomeado por ter sido realizado pelo economista Nicholas Stern, do Banco Mundial, ganhou repercussão no meio empresarial por demonstrar os ganhos que poderiam ser obtidos por meio da produção ambientalmente responsável. Uma das principais conclusões a que se chega no relatório é que, com um investimento de apenas 1\% do PIB Mundial, se pode evitar a perda de $20 \%$ do mesmo PIB, num prazo de simulação de 50 anos (STERN, 2006).
} 
vs. população fora do mercado de consumo; aquecimento global, mudanças climáticas, destruição de certas espécies, a escassez de água, catástrofes e perdas humanas e econômicas delas decorrentes. O tema do desenvolvimento sustentável é trabalhado junto com o de responsabilidade na seguinte equação: "RSE $=+$ desenvolvimento sustentável" (ULLA, 2009), ou seja, a RSE é parte das estratégias para alcançar um maior nível de desenvolvimento sustentável. Normativamente, o social, o econômico e o ambiental são indissociáveis numa visão estratégica de desenvolvimento, sendo que a interface entre social e econômico deve resultar em equidade bem como a interface entre social e econômico com o ambiental deve resultar em viabilidade. Portanto, a sustentabilidade congrega a viabilidade econômica, perpetuação ecológica e a equidade social.

No entanto, o tema da sustentabilidade ambiental relaciona-se intimamente ao da sustentabilidade social. Na Argentina, destaca-se como parte desse grave problema: o aumento da desigualdade social; a situação de penúria de algumas populações do interior do país (sobretudo nas províncias do norte); a fome da população pobre nas grandes cidades; a pobreza relacionada à infância e à adolescência $(50 \%$ dos pobres do país são crianças ou adolescentes, entre os 10 milhões de crianças que habitam o país $57 \%$ são pobres e $25 \%$ são indigentes, pesquisas indicam que expectativa de futuro de jovens e adolescentes resume-se a pensar-se em trabalhos precários e subempregos, quando não "excluídos ou mortos", o sistema educativo não consegue conter os jovens que saem facilmente dele ou mantêm-se em situação de repetência, baixo aprendizado e sem transporte para as escolas principalmente no campo); trabalho infantil (fábricas de tijolos, construção civil, colheitas, indústria têxtil e trabalhos domésticos) e exploração sexual de crianças no âmbito do turismo; trabalho forçado e trabalho escravo. Outro tema relacionado com o chamado calentamiento social (aquecimento social) que recebe grande ênfase no trabalho, por exemplo, do Instituto Argentino de Responsabilidad Social Empresaria (IARSE) é o das pessoas portadoras de deficiências (discapacidad), um contingente aproximado de 2,2 milhões de pessoas (segundo dados do Relevamiento Infraestructura Escolar do Gobierno de la Ciudad de Buenos Aires) que têm acesso negado à escola, ao transporte público, ao trabalho e ao lazer, o que as coloca em situação de enorme desigualdade social.

Já no caso do Brasil, a mudança estratégica para a sustentabilidade significou de fato a priorização das temáticas ambientais em detrimento de temáticas sociais. Mas há diferenças substantivas no entendimento desse conceito, e disputas de sentido que 
permeiam sua construção no debate público. Para a Fiesp, por exemplo, a ênfase recai sobre o fato de que a sustentabilidade ambiental é a sustentabilidade do negócio. Sob o molde do utilitarismo, nota-se que para além do conteúdo humano e ambiental, o resultado mais palpável das ações de cunho ambiental é a economia de recursos e os consequentes ganhos de competitividade, o que as tornam não um ônus, mas um bônus A diretora do Comitê de Responsabilidade Social (Cores) garante que o tema da sustentabilidade tem ganhado espaço e ficado cada vez mais forte no meio empresarial porque ele tem um resultado tangível:

[...] é bom para o ser humano, bom para o meio ambiente, bom para o consumidor e bom para os negócios. No início, o empresariado seguia a legislação ambiental a contra gosto porque era lei. Hoje, os empresários fazem mais do que está previsto na lei por causa do retorno. (BELFORT, 2009).

Já para o Ethos, a ênfase recai sobre a luta política por um mercado ou uma economia verde, inclusiva e responsável; da responsabilidade social como luta pela justiça social à responsabilidade social como luta pela sustentabilidade e projeção do Brasil no cenário internacional - tem por objetivos: "[...] criar referências de experiências empresariais em sustentabilidade, gerar cooperação entre as empresas participantes e mostrar evidências concretas de que é possível unir RSE ao desempenho positivo das empresas." (INSTITUTO ETHOS..., 2009, p. 12). A guinada rumo à defesa da sustentabilidade é ainda respaldada pela decisão de integrar as empresas, as cidades brasileiras e os projetos nacionais na construção de um mercado e de uma sociedade sustentáveis. Para isso, há um esforço coordenado em iniciativas como Grupo Referencial de Empresas pela Sustentabilidade (GRES), o Movimento Nossa São Paulo, o Fórum Amazônia Sustentável e o projeto Conexões Sustentáveis (INSTITUTO ETHOS..., 2009). A grande distinção entre as duas visões é que, no caso do Ethos, a questão social passa a estar integrada ao tema do desenvolvimento sustentável, enquanto, para a Fiesp, a questão da sobrevivência dos negócios é que passa a estar integrada ao desenvolvimento sustentável.

Tal como vimos em relação à questão social, discuti-la e resolvê-la diz respeito a uma imaginação mais ampla do que é a nação, incluindo, portanto, um projeto de país. No caso argentino, a ausência de uma disputa pública entre visões divergentes coloca o tema da sustentabilidade distante de um projeto de nação: é coisa do interior das empresas. No caso do Brasil, as disputas de sentido e os tensionamentos em torno da 
sustentabilidade que se dão no debate público e na sua emergência como problema social colocam-nos frente a frente com maneiras diferentes de organizar a relação entre público e privado. Quando a relação é mais horizontal, vemos emergir uma visão do Brasil como uma potência construída com base numa economia verde, inclusiva e responsável. Quando a relação é vertical e a prioridade lógica é dada ao privado e não ao público, vemos Brasil como uma grande potência econômica com base numa economia industrial com tecnologia de ponta financiada pelo Estado para colocar-se como nação competitiva no cenário internacional.

\section{Considerações Finais}

O que a perspectiva histórica nos sugere é que o social é objeto de disputas de ambas as elites econômicas - a brasileira e a argentina. Porém no caso brasileiro há uma atuação direta dos empresários nas estruturas estatais, através de cargos eletivos e de importantes estruturas de lobby e de relacionamento com a burocracia (os empresários "querem ser Estado", ou seja, ocupar a posição de controle e hegemonia no espaço público via aparato estatal). No caso argentino, por sua vez, a atuação é indireta e os empresários utilizam a mediação das organizações da sociedade civil para fazerem valer seus interesses e objetivos de controle e hegemonia no espaço público (as organizações da sociedade civil é que "querem ser Estado").

Tais características tiveram implicações na maneira como a mobilização pela RSE ocorreu nos dois casos em foco. No caso do Brasil, a liderança é empresarial, enquanto na Argentina a liderança é da sociedade civil. Essa diferença se explica a partir do processo histórico que revela uma maior aproximação do empresariado brasileiro às coisas públicas - ainda que por vias não convencionais como a políticopartidária - que a do empresariado argentino, mais resignado à esfera dos negócios acomodando-se aos sucessivos governos. Já a sociedade civil argentina, muito mais articulada e ativa no espaço público que a brasileira, supõe-se "dona" da questão social, cabendo a ela liderar o processo de intervenção social das empresas até porque "resisten a unarchivo"4 e, com isso, contam com a credibilidade da sociedade. Há que se ressaltar ainda que a liderança brasileira é marcada pela presença do Ethos no campo, referência não só para o Brasil, mas para a Argentina (e outros países) que é uma entidade

\footnotetext{
${ }^{4}$ Essa expressão significa que podem ser investigadas, que têm um passado limpo, diferentemente do que ocorre com empresários e empresas.
} 
empresarial não de molde corporativista mas atuante como grupo organizado da sociedade civil.

O reconhecimento da questão ambiental como problema prioritário à mobilização empresarial e da sociedade civil, deve ser, por si, visto como um avanço importante. Porém é preciso observar e examinar com mais acuidade o que está em jogo nas visões das lideranças. No caso argentino, a mudança de foco para a sustentabilidade parece apenas acompanhar uma tendência internacional, talvez até sob influência do Brasil, mas aponta para uma interessante combinação entre problemas sociais e problemas ambientais. No caso brasileiro, a passagem é mais marcada e é preciso ver que continuam a existir interpretações diferentes sobre a sustentabilidade de seu papel na construção da nação imaginada. A disputa interna no segmento empresarial, notada no caso do Brasil, representa, nesse sentido, a possibilidade de circulação das elites. Mas, por outro lado, o fato dessa dimensão política da RSE e da sustentabilidade ser pouco discutida, inclusive pelos próprios atores, não contribui para um aprofundamento democrático mais radical uma vez que a simples divergência de projetos precisa ser combinada com a participação ampliada - daí a centralidade do tema da nação.

São duas visões que espelham os contextos históricos particulares nos quais a noção de RSE, aparentemente, pasteurizada nos parâmetros da globalização e integrada à chamada cultura de negócios (BARBOSA, 2002), ganha especificidades nas suas vertentes de ênfase no social e no ambiental. O contraste dos discursos nos dois países pode contribuir para a análise política da questão, uma vez que envolve disputas diversamente organizadas do ponto de vista do seu conteúdo, porém, estruturalmente parecidas (envolvem os mesmos atores, os mesmos termos, o mesmo campo de problemas). Estudos comparativos que levem em consideração a avaliação histórica do enraizamento da RSE - como discutimos - em outras realidades poderão enriquecer nosso conhecimento do tema, ampliando a capacidade de descrevê-lo e analisá-lo adequadamente. 


\title{
From the social to the environmental: the mobilization for corporate social responsibility in Brazil and Argentina through a comparative historical perspective
}

\begin{abstract}
The attempt of the following article is to understand why the business community have assumed the control of the dissemination of discourses and practices of CSR in Brazil, while in Argentina the same has been done by the civil society. Thereby, apart from the comparative effort - always useful to indicate similarities and differences create scales and suggest generalizations - it is easy to have a comprehension about the existence of a gap while addressing the issue, which needs to be suppressed: a landmark construction regarding business action in relation to the social question. As a corollary, we intend to apprehend the contextual framework of meanings related to the term CSR in each national reality were they were analyzed, as well as pointing how this question have morphed from the social question, to the environmental one, taking into consideration the fact that, although being a global discourse, it is far from being homogeneous or undiversified.
\end{abstract}

Key words: Corporate Social Responsibility; Social Issues; Sustainability; Compared history; Brazil; Argentina.

\section{Referências}

AGÜERO, Felipe. Business Social Responsibility in Latin America: Argentina, Brazil, Chile, Colômbia, México and Peru. Miami: School of Internacional Studies/University of Miami, 2002 (Report for Ford Foundation).

BARBOSA, Lívia. Globalização e Cultura de Negócios. In: KIRCHNER, Ana Maria; GOMES, Eduardo R.; CAPPELLIN, Paola (Org.). Empresa, Empresários e Globalização. Rio de Janeiro: Relume-Dumará/FAPERJ, 2002.

BELFORT, Eliane. Entrevista concedida a Rosa Diniz. Disponível em: $\langle$ http://www.youtube.com/results?search_query=Eliane+Belfort\&search_type=\&aq=f $>$. Acesso em 01/10/2009.

BLUMER, Herbert. Social Problems as Collective Behavior. Social Problems, Berkeley, University of California Press/Society for the Study of Social Problems, v. 18, n. 3, p. 298-306, 1971.

CAMPETELLA, Andrea; BOMBAL, Inés González. Historia del Sector sin Fines de Lucro en Argentina. In: ROITTER, Mario; BOMBAL, Inés Gonzalez. Estudios sobre el Sector Sin Fines de Lucro en Argentina. Buenos Aires: CNPJHU-CEDES, 2000a.

CAMPETELLA, Andrea; BOMBAL, Inés González. El desarrollo histórico del sector sin fines de lucro en Argentina: debate com algunos modelos teóricos. In: ROITTER, Mario; BOMBAL, Inés Gonzalez. Estudios sobre el Sector Sin Fines de Lucro en Argentina. Buenos Aires: CNPJHU-CEDES, $2000 \mathrm{~b}$. 
CARDOSO, Fernando Henrique. Ideologías de la burguesia industrial en sociedades dependientes (Argentina y Brasil). México: Siglo XXI Editores, 1971.

CARDOSO JR., José Celso; JACCOUD, Luciana. Políticas sociais no Brasil: organização, abrangência e tensões da ação estatal. In: JACCOUD, L. (Org.). Questão social e políticas sociais no Brasil contemporâneo. Brasília: IPEA, 2005.

CARVALHO, José Murilo. Os bestializados: o Rio de Janeiro e a república que não foi. São Paulo: Companhia da Letras, 1987.

INSTITUTO ETHOS/INSTITUTO AKATU. Práticas e Perspectivas da Responsabilidade Social Empresarial no Brasil: sumário de pesquisa. São Paulo, Ethos/Akatu/Ibope Inteligência, Jul., $2009 . \quad$ Disponível em: <http://www1.ethos.org.br/EthosWeb/arquivo/0-A30Prat_perspc_RSE_pesq2008.pdf>. Acesso em: 13 set. 2009.

FAUSTO, Boris; DEVOTO, Fernando. Brasil e Argentina: um ensaio de história comparada (1850-2002). São Paulo: Editora 34, 2004.

FERNANDES, Florestan. A Revolução Burguesa no Brasil: ensaio de interpretação sociológica. Rio de Janeiro: Zahar Editores, 1975.

FORUM EMPRESA. Estado de la Responsabilidad Social Empresarial en América Latina bajo la mirada de ejecutivos de empresas. Chile, 2009.

GLIK, Mônica Sol. Ordem e Progresso, Civilização e Barbárie. Perón, Vargas e Positivismo. (Argentina-Brasil, 1930-1955). Monografia (Conclusão de curso) Universidade Autônoma de Madrid, s/d.

GOMES, Ângela Maria de Castro. Burguesia e trabalho: política e legislação social no Brasil, 1917-1937. Rio de Janeiro: Campus, 1979.

HARVEY, David. Condição Pós-Moderna. 10. ed. São Paulo: Edições Loyola, 2001.

HORA, Roy. Empresarios y política en la Argentina, 1880-1916. In: SIMPOSIO 46, BUSINESSORGANIZATIONSANDPOLITICALECONOMYOFF XXTHCENTURY Y LATINAMERICA, del XIII Congress of the Internacional Economy History Association. Buenos Aires, jul. 2001.

INSTITUTO DE PESQUISAS ECONÔMICAS APLICADAS. A iniciativa privada e o espírito público: a evolução da ação social das empresas nas regiões Sudeste e Nordeste. Brasília: Rede IPEA de Pesquisa/BID/Escritório da CEPAL no Brasil, jun./2005. Disponível em <http://www.ipea.gov.br/acaosocial/IMG/pdf/doc-23.pdf>. Acesso em: 16 jan. 2008.

INSTITUTO DE PESQUISAS ECONÔMICAS APLICADAS. A iniciativa privada e o espírito público: a evolução da ação social das empresas no Brasil. Brasília: Rede IPEA de Pesquisa/BID/Escritório da CEPAL no Brasil, jul./2006. Disponível em <http://www.ipea.gov.br/acaosocial/IMG/pdf/doc-28.pdf >. Acesso em: 16 jan. 2008. 
JÁUREGUI, Aníbal Pablo. Élites Empresarias y Políticas de Desarrollo: Brasil y Argentina - 1920-1955. 2001. Tesis (Doctorado) - Universidad Nacional del Centro de la Provincia de Buenos Aires, Tandil.

OLIVEIRA, José Antônio Puppim de. Corporate citizenship in Latin America: new challenges for business. Journal of Corporate Citizenship, Sheffield-UK, n. 21, p. 17-20, 2006.

OLIVEIRA, Luciana de. Ideias do presente, práticas do passado? Elites empresariais e a questão social no Brasil e na Argentina - estudo comparativo de discursos e práticas de Responsabilidade Social Empresarial. 2010. 440f. Tese (Doutorado em Ciências Humanas: Sociologia e Política) - Universidade Federal de Minas Gerais, Belo Horizonte.

PALADINO, Marcelo; MOHAN, Anupama. Tendencias de la Responsabilidad Social Empresaria en Argentina. Buenos Aires: Escuela de Dirección y Negocios de la Universidad Austral, jun., 2002 (Documento de Investigación).

PASSANANTE, María Ines. Pobreza y Acción Social en la Historia Argentina: de la beneficencia a la seguridad social. Buenos Aires: Editorial Humanitas, 1987.

PELIANO, Anna Maria T. Medeiros (Coord.). A iniciativa privada e o espírito público.Um retrato da ação social das empresas do Sudeste brasileiro. Brasília: IPEA, 2000 .

PELIANO, Anna Maria T. Medeiros. Bondade ou Interesse? Como e porque as empresas atuam na área social. Brasília: IPEA, 2001ª .

PELIANO, Anna Maria T. Medeiros. A iniciativa privada e o espírito público. Um retrato da ação social das empresas do Nordeste brasileiro. Brasília: IPEA, 2001b.

PELIANO, Anna Maria T. Medeiros. A iniciativa privada e o espírito público. Um retrato da ação social das empresas do Sul do Brasil. Brasília: IPEA, 2001c.

QUIROGA, Ana Maria. Assistência e Poder. Revista Praia Vermelha: estudos de política e teoria social. Escola de Serviço Social da Universidade Federal do Rio de Janeiro, n. 18, p. 14-28, jan./jun. 2008.

RED INTERAMERICANA DE RSE. Situación de la RSE en Latinoamérica hacia un desarrollo sustentable.Valparaíso-Chile: Red Interamericana de RSE/VincularPUC Valparaíso, sep. 2005.

RED PUENTES. Visión y Propuestas de Red Puentes sobre la Tarea de la Responsabilidad Social Empresarial en América Latina. 2004.

ROMERO, Luis Alberto. Breve Historia Contemporánea de la Argentina. 2. ed. Buenos Aires: Fondo de Cultura Econômica, 2001.

ROMERO, José Luis. Breve Historia de la Argentina. 5. ed. Buenos Aires: Fondo de Cultura Econômica, 2004. 
ROUQUIÉ, Alain. Introdução geral: querer a democracia. In: ROUQUIÉ, A., LAMOUNIER, B. E SHVARZER, J. (Org.). Como renascem as democracias. São Paulo: Editora Brasiliense, 1985.

ROITTER, Mário, El mercado de la beneficencia: algunas evidencias sobre las características y dimensión de la filantropía empresaria en la Argentina. In: THOMPSON, Andrés (Comp.). Público y privado: las organizaciones sin fines de lucro en Argentina. Buenos Aires: Losada/Unicef, 1995.

SIKKINK, Kathryn. Las capacidades y la autonomia del estado en Brasil y la Argentina: un enfoque neoinstitucionalista. Desarrollo Económico, v. 32, n. 128, enero-marzo, 1993.

STERN REVIEW: The Economics of Climate Change, 2006.

THOMPSON, Andrés. Beneficencia, Filantropía y Justicia Social: el tercer sector en la historia argentina. In: THOMPSON, Andrés (Comp.). Público y privado: las organizaciones sin fines de lucro en Argentina. Buenos Aires: Losada/Unicef, 1995.

TRINDADE, Hélio. Bases da democracia brasileira: lógica liberal e práxis autoritária. In: ROUQUIÉ, A., LAMOUNIER, B. e SHVARZER, J. (Org.). Como renascem as democracias. São Paulo: Editora Brasiliense, 1985.

VALLADARES, Lícia. Cem Anos pensando a pobreza (urbana) no Brasil. In: BOSCHI, Renato (Org.). Corporativismo e Desigualdade: a construção do espaço público no Brasil. Rio de Janeiro: Rio Fundo Editora-IUPERJ, 1991.

VISCARDI, Cláudia Maria Ribeiro; JESUS, Ronaldo Pereira de. A experiência mutualista e a formação da classe trabalhadora no Brasil. In: FERREIRA, Jorge; REIS, Daniel Aarão. A Formação das Tradições (1889-1945). Rio de Janeiro: Civilização Brasileira, 2007 (Coleção As esquerdas no Brasil, v. 1). 